\title{
EVALUATION OF SHORT TERM RESULTS IN INTRACAPSULAR FRACTURE NECK FEMUR TREATED BY VARIABLE LENGTH SLIDING COMPRESSION SCREW FIXATION (VLSC SCREW)
}

Sanjay Kumar Gupta1 ${ }^{1}$ Utkal Gupta², V. P. Pathania ${ }^{3}$, Arjun Gandotra ${ }^{4}$

\section{HOW TO CITE THIS ARTICLE:}

Sanjay Kumar Gupta, Utkal Gupta, V. P. Pathania, Arjun Gandotra. "Evaluation of Results in Intracapsular Fracture Neck Femur Treated by Variable Length Sliding Compression Screw Fixation (VLSC Screw)". Journal of Evolution of Medical and Dental Sciences 2014; Vol. 3, Issue 11, March 17; Page: 2950-2956,

DOI: $10.14260 /$ jemds/2014/2228

ABSTRACT: We describe a method of internal fixation for femoral neck fractures which has been newly developed to reduce the frequency of complications like back out, hip joint protrusion and implant failure of cannulated hip screws. Two variable length sliding compression screws are inserted in the axis of femoral neck to reach into the subchondral bone of femoral head. The screws are inserted over guide pins and the tip of screws are self-tapping and these are designed in such a way that the inner screw slides into the outer barrel to manage the collapse of bone at fracture site. The present study is of 15 cases and these cases were followed for 18 months. All fractures in union cases healed within 6 months. There was no case of late segmental collapse non-union. Functional evaluation was done on the basis of Harris hip score (HHS), according to which 8 cases had excellent, 4 cases had good and 3 cases had poor results due to avascular necrosis and non-union.

KEYWORDS: Variable length sliding compression screws, femoral neck fracture, Intracapsular.

INTRODUCTION: Fractures of Hip are relatively common injuries in elderly. The incidence of hip fractures is increasing, which is not unexpected because the life expectancy of the population has increased significantly during past decades (Cooper and Melton, 1992). ${ }^{1}$ These fractures are associated with substantial morbidity and mortality; 30\% of elderly patients die within 1 yr. of fracture (Aharanott et al 1997). ${ }^{2}$ Intracapsular femoral neck fractures account for about $50 \%$ of all hip fractures. Nearly 9 of 10 fractures occur in patients older than 65 yrs. old are more common in women (Aitken 1988). ${ }^{3}$

Mostly hip fractures occur in elderly individuals as a result of only moderate or minimal trauma. $90 \%$ of cases are due to fall and the causes of falls include decrease physical activity, decreased reaction time and poor vision. In younger patients, these fractures usually result from high energy trauma (Astron et al, 1987). ${ }^{4}$

Despite ever-increasing literature on hip fracture, there are no authoritative and evidencebased guidelines for the management of displaced intracapsular femoral femoral neck fractures (FNF). ${ }^{5}$

A general lack of consensus exists among orthopedic trauma surgeons in the management of these fractures. ${ }^{6}$ The decision making in hip fracture treatment depends on age, patient's comorbidities, pre-fracture configuration and pre-existing degenerative status of the joint. ${ }^{7-10}$

The present consensus is that in patients with fracture neck of femur below 60 years of age should be treated with internal fixation, and arthroplasty should be reserved for elderly patients above 80 years, 60 to 80 years old patients with displaced fracture neck of femur still remain a grey zone.11 Femoral neck fractures are almost invariably treated with internal fixation in young 
individuals (<65 yrs. age) (Haiduckewych et al, 2004).12 Fixation by cannulated hip screws has become gold standard (Booth et al. 2998), ${ }^{13}$ but some problems like back out, hip joint protrusion, Implant failure are associated with these screws(VLSC). ${ }^{14}$

Fracture neck of femur itself is also associated with complication like avascular necrosis of head, non-union but early fixation and assessment of posterior comminution can improve prognosis. ${ }^{15-16}$

Keeping in view, the post-operative complications of cannulated hip screw, we have undertaken a study in which fracture fixation was done by newly modified cannulated screws variable length sliding compression screw (VLSC).

MATERIAL AND METHOD: This is a prospective study of 15 patients, 6 female and 9 male, with age between 20 to 70 years, with 6 Garden grade II, 8 grade III and 1 grade IV type of fractures. The patient selection criteria for screw fixation were: age more than 20 years, displaced fracture neck of femur, no radiographic evidence of pathological fracture, and independently mobile patient without neuromuscular disorder or cognitive impairment and without any metabolic bone disease. There was no upper age limit for patient selection.

The VLSC screw has inner screw diameter of $6.5 \mathrm{~mm}$ and outer barrel diameter of $8.5 \mathrm{~mm}$ and it has two variable length's (a) $59 \mathrm{~mm}-75 \mathrm{~mm}$ and (b) $76 \mathrm{~mm} \mathrm{-110} \mathrm{mm} \mathrm{(minimum} \mathrm{length} \mathrm{-}$ maximum length). It has a self-tapping tip. Inner screw slides in the outer barrel. Outer barrel has 3 grooves that fit into lateral cortex.

Under regional anesthesia/GA the procedure was carried out on standard orthopedic fracture table in supine position under $\mathrm{C}$-arm control, the fracture was reduced by close manipulation and limb was kept in internal rotation.

The lateral femoral cortex was exposed by reflecting vastus lateral is anteriorly and first guide wire was put at the level of lesser trochanter. Initial reaming was done by inner cannulated reamer till $5 \mathrm{~mm}$ from subchondral bone. Then outer reamer was placed and reaming was done for outer barrel. Then VLSC screw was assembled to extended "T" wrench and screw was advanced till 5 $\mathrm{mm}$ from subchondral bone. Now with the help of standard "T" wrench, outer barrel was gently pushed till the outer grooves fitted into the lateral cortex.

Same procedure was done for other screw. Lastly with the help of compression rod, the compression at fracture site was achieved. Hip and Knee mobilization and quadriceps exercises were allowed on $1^{\text {st }}$ post-operative day and non-weight bearing walk was allowed on $5^{\text {th }}$ post-operative.

Patients were reviewed at 3, 4, 6 and 12 months with clinical and radiological examination and again at 18 months. Complications were assessed and recorded as they occurred.

RESULTS: In this study we evaluated results of VLSC Screw fixation in 15 cases of intracapsular fracture neck of femur. The age of patients varied from 20-70 years, the average age was 46 years and $60 \%$ case were males. According to garden grading, 6 cases were of grade II, 8 cases were of grade III and 1 was of grade IV. 46.6\% cases were having severe osteoporosis i.e. Singh's index < grade 3. All patients were operated within 6 days. Patients were followed up to 18 months. 13 cases in this study achieved union, out of which $67 \%$ achieved union in 3-4 months, $27 \%$ in $4-5$ months and $6 \%$ in $5-6$ months. Functional evaluation was done on Harris hip score (HHS). 8 cases had functionally excellent, 4 cases had good and 3 cases had poor results. These poor results were due to occurrence of 
avascular necrosis of the head of femur in 1 case and non-union in 2 cases. There were no cases of late segmental collapse, back out and protrusion of screws into hip joint.

The slide of inner screw in the barrel is also calculated (table 1). This slide corresponds to the collapse of bone at fracture site.

\begin{tabular}{|c|c|c|}
\hline \multirow{2}{*}{ Amount of Slide (mm) } & \multicolumn{2}{|c|}{ No. of cases } \\
\cline { 2 - 3 } & Upper screw & Lower screw \\
\hline $0-2$ & 6 & 3 \\
\hline $2-4$ & 2 & - \\
\hline $4-6$ & 4 & 5 \\
\hline $6-8$ & - & 3 \\
\hline $8-10$ & - & 1 \\
\hline $10-15$ & 3 & - \\
\hline $15-20$ & - & 1 \\
\hline \multicolumn{2}{|c|}{ TABLE 1: AMOUNT OF SLIDING } \\
\hline
\end{tabular}

DISCUSSION: The age and sex of the patient, osteoporosis, degree of fracture displacement and the quality of fracture reduction have been found to affect the end results. Taking these factors together, it is quite likely that the method of Osteosynthesis influences the prognosis (stromquvist and Hansson 1982). Prior to any fixation, it is of utmost importance to achieve a stable reduction. In stable reduction, it should be slight valgus reduction to reduce the amount of shear forces and it should ensure good cortical contact on the medial side to counteract the bending stress.

It is described by the AO/ASIF group (1958) that there are 2 principle methods of achieving good internal fixation - (1) Splinting (2) Collapse and Inter fragmentary compression. In our series, we tried to compare VLSC screws to CCS screws. Out of the 15 cases with an average age of 46 years, $60 \%$ were males. Six fractures were of Garden grade II, 8 were of grade III and one was of grade IV. 13 cases in this study achieved union, $67 \%$ achieved union in 3-4 months, $27 \%$ in $4-5$ months and $6 \%$ in 5-6 months. In study of CCS screw fixation by Alok Sud et al, a series of 30 cases, $80 \%$ achieved union while $20 \%$ remained un-united at 9 months follow up.

Loosening of screws was observed in two patients while in our series there was no loosening or back out of screws. In our series AVN was seen in one patient (10\%) like in CCS series in which it was seen in 3 patients (10\%) and nonunion was seen in 2 cases (14\%) in contrast to CCS series in which it was seen in 6 patients (20\%). Asnis (1994) used CCS for fixation of fracture neck of femur after closed reduction. He reported nonunion in $4 \%$ cases and AVN in $22 \%$ cases.

CONCLUSION: The results of union using VLSC screw fixation are better than cannulated hip screws fixation due to easy collapse at fracture site. It also has some advantages over CCS screw fixation as follows:

1. It can bear more bending stresses because it slides before bending, so there is a less chance of implant breakage.

2. It provides dynamic inter-fragmentary compression and well adjusts the collapse of bone by sliding into outer barrel.

3. It has self- tapping tip, so chances of rotation of head during insertion are minimal. 
4. With only 2 sizes of screw, hospital stocks can be rationalized

5. Because of the presence of lateral grooves in outer barrel and sliding of inner screw, back out and protrusion in the joint is prevented.

Thus these screws can provide better alternative to CCS, however a larger prospective randomized study to assess the results and complications will be needed.

\section{BIBLIOGRAPHY:}

1. Cooper C, Melton U. Hip fractures in elderly: a world- wide projection. Osteoporosis Int 1992; 2: 285-9.

2. Aharanott. GB, Koral Kj, skovron ML, et al. Hip fractures in the elderly: predictors of one year mortality, J orthopaedic trauma 11:162, 1997.

3. Aitken JM. Relevance of osteoporosis is women with fracture of femoral neck, BMJ 288: 597, 1988.

4. Astron J, Ahnqvist S, Beertema J, et al. Physical activity in women sustaining fracture of neck of the femur, J Bone joint surg. 69B:381, 1987.

5. Khan M, Aleem IS, Poolman RW. Fixation versus primary replacement of displaced femoral neck fractures in the elderly. Indian J Orthop; 45:23-6, 2011.

6. Kakar S Tornetta P 3rd, Schemitsch EH, Swiontkowski MF, Koval K Hanson BP, et al. International Hip Fracture Research Collaborative. Technical considerations in the operative management of femoral neck fractures in elderly patients: A multinational survey. J Trauma;63: 641-6, 2007.

7. Pal DK. Fracture neck of femur- Is It still Unsolved?. Indian J Orthop; 38:221-5, 2004.

8. Sandhu HS. IOA WHITE PAPER: Management of fracture neck of femur, Indian J Orthop; 39:1306, 2005.

9. Sandhu HS, Dhillon MS, Jaing AK. Femoral neck fractures. Indian J Orthop; 42:1-2, 2008.

10. Miyamoto RG, Kaplan KM, Leving BR, Egol KA, Zukerman JD. Surgical management of hip fractures of hip fractures: An evidence-based review of the literature. I: Femoral neck fractures. J Am Acad Orthop Surg; 16:596-607, 2008.

11. Bhandari M, Devereaus PJ, Tornetta P $3^{\text {rd }}$, Swiontkowski MF, Berry DJ, Haidukewych G, et al. Operative management of displaced femoral neck fractures in elderly patients. An international survey. J Bone joint Surg Am; 87:2122-30, 2005.

12. Haiduckewych GJ, Rothwell WS, Jacofsky DJ, et al. Operative treatment of femoral neck fractures in patients between the ages of fifteen and fifty years, J Bone Surg 86 A: 1711, 2004.

13. Booth KC, Donald son KJ, Dai QJ. Femoral neck fracture fixation: a biomechanical study of two cannulated screw placement techniques, orthopaedics 21:1173, 1998.

14. Stappaerts KH, Broos PL. Internal fixation of femoral neck fractures. A follow up study of 118 cases. Acta chir Belg 1987; 87: 24.7-51.

15. Razik F, Alexopoulos AS. Time to internal fixation of femoral neck fractures in patients under sixty years-does this matter in the development of osteonecrosis of femoral head? In Orthop. 36(10):2127-32, 2012.

16. Rawall S, Bali K, Factors affect the outcome in fracture neck of femur. Arch orthop Trauma Surg.132 (1): 73-9, 2012. 


\section{ORIGINAL ARTICLE}

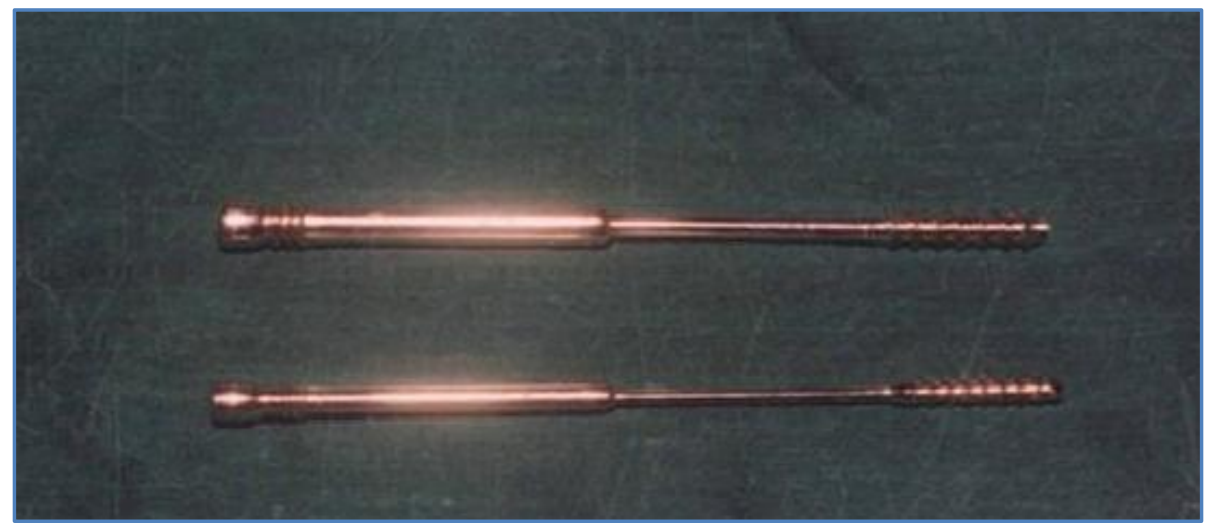

VARIABLE LENGTH SLIDING COMPRESSION SCREWS
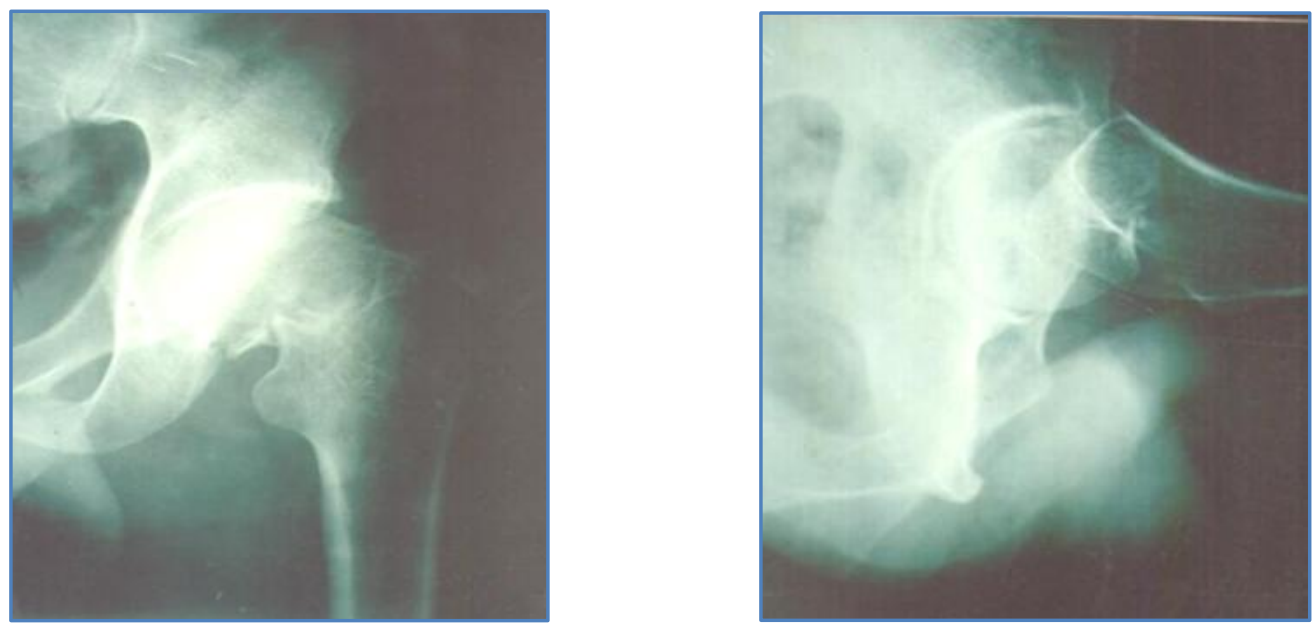

PREOPERATIVE LATERALSKIAGRAM
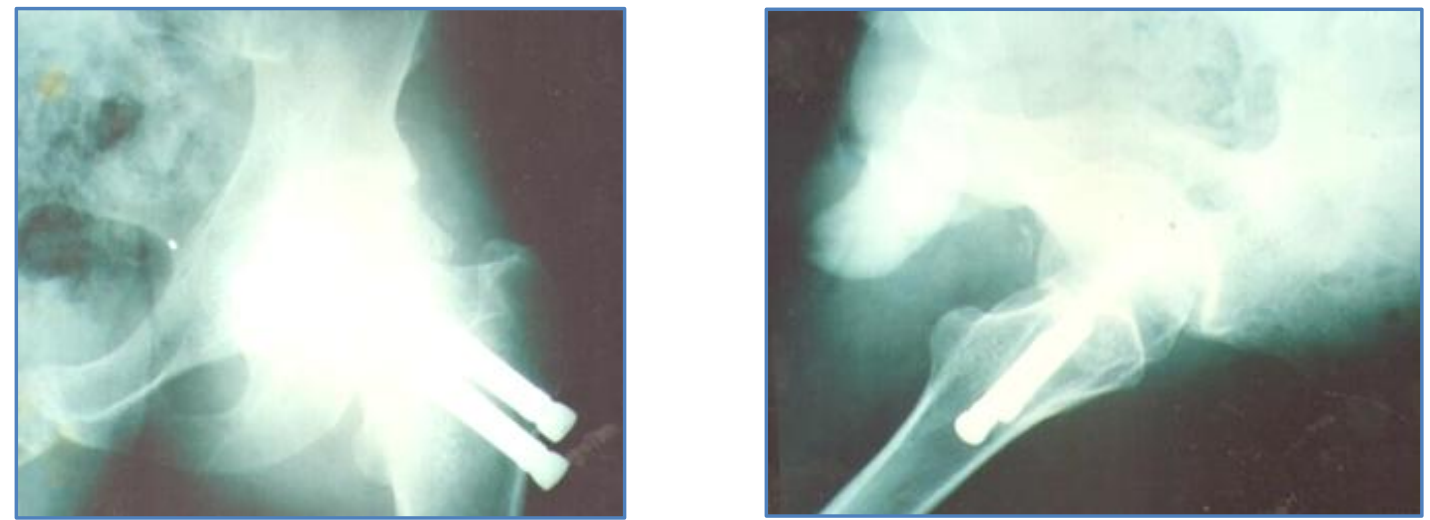

PREOPERATIVE A. P. SKIAGRAM PREOPERATIVE LATERAL SKIAGRAM 


\section{ORIGINAL ARTICLE}
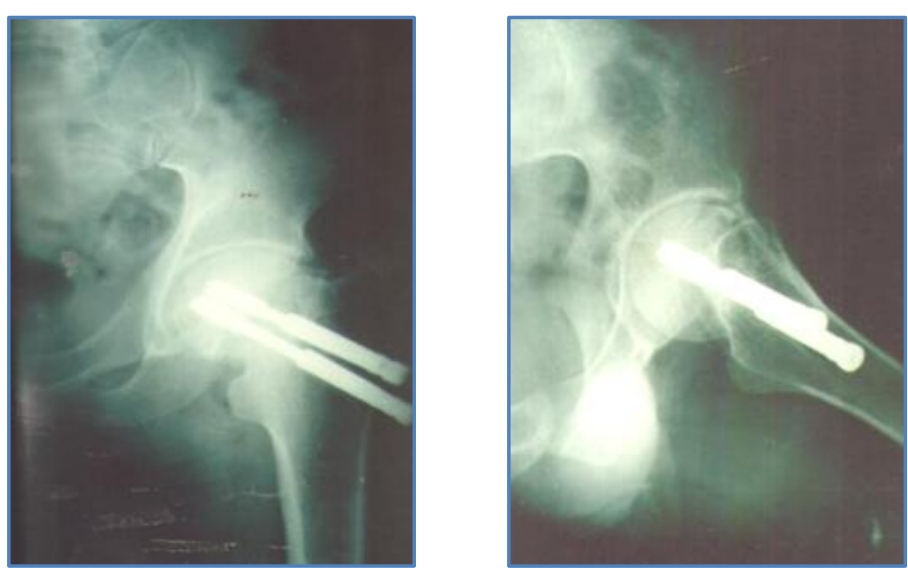

FOLLOWUP SKIAGRAM AFTER 18 MONTHS
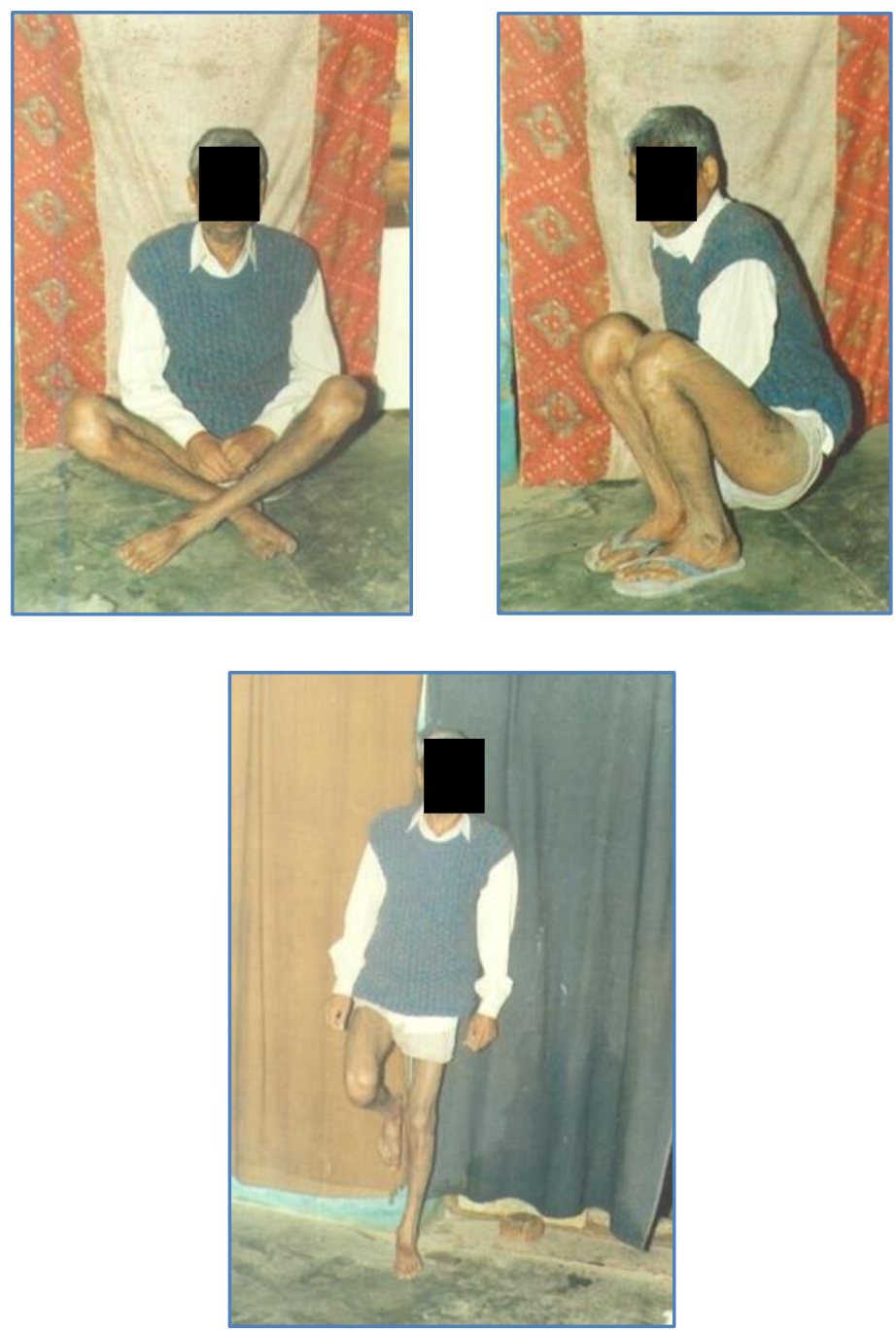

PHOTOGRAPHS SHOWING FUNCTIONAL RESULTS 


\section{ORIGINAL ARTICLE}

\section{AUTHORS:}

1. Sanjay Kumar Gupta

2. Utkal Gupta

3. V.P. Pathania

4. Arjun Gandotra

\section{PARTICULARS OF CONTRIBUTORS:}

1. Associate Professor, Department of Orthopaedics, Shri Ram Murti Smarak Institute of Medical Sciences, Bareilly.

2. Associate Professor, Department of Orthopaedics, Shri Ram Murti Smarak Institute of Medical Sciences, Bareilly.

3. Professor, Department of Orthopaedics, Shri Ram Murti Smarak Institute of Medical Sciences, Bareilly.
4. Resident, Department of Orthopaedics, Shri Ram Murti Smarak Institute of Medical Sciences, Bareilly.

\section{NAME ADDRESS EMAIL ID OF THE CORRESPONDING AUTHOR:}

Dr. Sanjay Gupta,

Associate Professor,

Shri Ram Murti Smarak Institute of Medical

Sciences,

Bareilly - 243202.

E-mail: dr.sanjaygupta@ymail.com

Date of Submission: 02/01/2014. Date of Peer Review: 03/01/2014. Date of Acceptance: 22/02/2014.

Date of Publishing: 17/03/2014. 